\title{
Nodulation Compatibility and Symbiotic Performance of Rhizobia spp. With Different Landraces of Bambara Groundnut (Vigna Subterranea (L.) Verdc.) Collections
}

Ahmed Idris Idris Hassen ( $\sim$ HassenA@arc.agric.za )

Agricultural Research Council https://orcid.org/0000-0001-6925-9166

Ansa van Vuuren

Agricultural Research Council, Plant Health and Protection

Francina Lebogang Bopape

Agricultural Research Council, Plant Health and Protection

Abe Shegro Gerrano

Agricultural Research Council, Vegetable, Industrial and Medicinal Plants

\section{Research Article}

Keywords: Nodulation, Nitrogen fixation, Bambara groundnut, Rhizobium, Host specificity

Posted Date: January 11th, 2022

DOI: https://doi.org/10.21203/rs.3.rs-1233082/v1

License: (c) (1) This work is licensed under a Creative Commons Attribution 4.0 International License.

Read Full License 


\section{Abstract}

The symbiosis of the legume bambara groundnut (Vigna subterranean L.Verde) with its rhizobial partners has not been studied sufficiently compared to several other legumes throughout Africa. In this study, a nodulation compatibility screening was conducted on 16 different landraces of this legume using five Rhizobia strains previously isolated from active nodules of Desmodium uncinatum, Arachis hypogaea, Cyamopsis tetragonoloba, Glycine max and Phaseolus vulgaris and deposited the South African Rhizobium Culture Collection (SARCC). A screening assay was conducted under glasshouse to select compatible rhizobia strains that nodulate and enhance growth in one or more genotypes of $V$. subterranean (L.) Verdc. Pre-germinated seeds of each landraces planted in sterile river sand medium were inoculated with $10^{8} \mathrm{cfu} \mathrm{ml}^{-1}$ of the rhizobial strains $(2 \mathrm{ml} / \mathrm{seed})$ and monitored with regular watering for six weeks. Parameters such as nodule number, nodule color and positions, plant biomass were determined in test genotypes. Significant differences were observed among landraces in nodule number and plant biomass, and among rhizobial strains in nodule number. Principal component analysis (PCA) showed that root nodule rhizobia strains SARCC-388 and SARCC-578 characterized as Bradyrhizobium zhangiangens and Bradyrhizobium centrosematis, respectively exhibited the highest nodulation compatibility with one or more bambara groundnut landraces. This study demonstrated that many of the bambara landraces did not show nodulation preference to a unique group of rhizobia, confirming that $V$. subterranean $(L)$ Verdc can be nodulated by more than one species of rhizobia, especially by rhizobia belonging to the cowpea miscellany cross inoculation group.

\section{Introduction}

While several agricultural research projects done in the past traditionally focused on staple crops, scientists in developed countries have given little attention to underutilized and neglected crop species. One such example of an underutilized crop is bambara groundnut (Vigna subterranea (L.) Verdc), a legume crop used for human consumption in many parts of the world particularly in Africa. Bambara groundnut is typically known to be an indigenous legume crop that grows in the African continent stretching from Kenya to Senegal and from the Sahara to South Africa and Madagaskar (Swanevelder 1998; Murevanhema and Jideani 2013). This legume is very well known for its advantages over many other legumes in terms of its high nutritional values and it is ranked as the third grain legume after groundnut and cowpea. The seed contains about $49 \%$ - $65 \%$ carbohydrate, $15-25 \%$ protein, $5.2 \%-6.4 \%$ fibre and $3.2 \%-4.4 \%$ ash and the bambara nut is known to be richer in essential amino acids than groundnut (Murevanhema and Jideani 2013; Mubaiwa et al. 2018). V. subterranean L. Verdc is cultivated either as a monoculture, in rotation with cereals or in mixed culture with cereals and is characterized by its drought tolerance and thrives in nutrient poor soils by forming effective root nodules with compatible rhizobia that can fix atmospheric nitrogen (N2) (Pouzaa et al. 2017). Due to its nutritional value, this underutilized legume represents a cheap plant based protein source that can improve the food and nutrition status of several households in Africa (Mubaiwa et al.2018). In addition to its nutritional value, the legume has drought tolerant characteristics, and according to previous controlled experiments, it is 
capable of producing significant yields under conditions where groundnut (Arachis hypogaea) fails to give similar yield results (Collison et al. 1997).

Biological Nitrogen Fixation (BNF), the process that converts atmospheric nitrogen $\left(\mathrm{N}_{2}\right)$ into ammonia, is the mechanism which $V$. subterranea $\mathrm{L}$. Verdc. uses to meet its nitrogen requirement like many other legumes. The process of BNF is executed by a group of soil bacteria commonly known as Rhizobia, which form a symbiotic association with legumes in specialized cells on roots known as nodules (Lindstroom and Mousavi 2020; Masson-Biovin and Sachs 2018). A major limitation of most research on underutilized crops such as bambara groundnut is that the research mainly focuses on a single aspect such as breeding of a particular landrace for the specific traits of interest. While research on breeding of legumes for traits such as yield is very essential, it is not always accompanied by nodulation and nitrogen fixation efficiency with a particular rhizobium species (Mkandawire 2007) towards combining these traits for improvement. It is obvious that the major objective of the agricultural use of legumes in research is to identify legume cultivars, strains of rhizobia or combinations of these for superior nodulation and nitrogen fixation capacity to increase productivity (Somasegaran et al.1989). Therefore, like in many other legumes, screening for nodulation and nitrogen fixation compatibility between diverse bambara groundnut genotypes and rhizobia is vital. One of the benefits of such types of research is that some positive response to specific rhizobia inoculation could be achieved if these rhizobia are inoculated in soils where the native rhizobia populations are not effective, but rather only competitive with less nitrogen fixation efficiency (Reinprecht et al. 2020).

In South Africa, bambara groundnut is usually produced by small-scale farmers and is largely produced in Limpopo, Mpumalanga, Kwa-Zulu Natal, Eastern Cape and North West Provinces (Masindeni 2006). However, due to the presence of several genotypes of bambara groundnut, the nodulation of the different genotypes by a given rhizobium species is not uniform for all the different landraces. In other words, just like several other legumes, there exists a variation in the symbiotic nitrogen fixation (SNF) ability of bambara groundnut landraces. It is therefore, very essential to identify bambara groundnut landraces with superior nodulation and nitrogen fixation ability that will greatly contribute to the reduction of the application of nitrogen fertilizers and also contribute to the bambara groundnut improvement programme in the country. No previous data are available for the cultivar-strain compatibility of bambara groundnut nodulation in South Africa. Here, we present a nodulation screening study to evaluate the symbiotic compatibility and/or nodulation specificity of 16 bambara groundnut landrace collections to different rhizobia strains, which are originally the micro symbionts of Glycine max (L.), Desmodium uncinatum, Arachis hypogaea, Phaseolus vulgaris and Cymopsis tetragonoloba.

\section{Materials And Methods}

\section{Planting materials}

The bambara groundnut ( $V$. subterranea L. Verdc.) landraces were obtained from the Agricultural Research Council Gene bank, South Africa. 16 different landraces of this legume were used in a 
glasshouse screening and characterization of five Rhizobia spp. for nodulation and nitrogen fixation across the various landraces.

Table 1

Description of the 16 bambara groundnut ( $V$. subterranea $L$. Verdc.) landraces used in the glasshouse assay for nodulation compatibility with five Rhizobia spp.

\begin{tabular}{|lllll|}
\hline No. & Entry & Landrace code & Growth habit & Seed color \\
\hline 1 & 34 & ZR S3 & Spreading type & Light brown \\
\hline 2 & 35 & ZR S4 & Semibunch type & Dark brown \\
\hline 3 & 36 & SB 11-1C & Spreading type & Cream white \\
\hline 4 & 37 & SB4-4G & Semibunch type & Light brown with black spot \\
\hline 5 & 38 & BB4-4H & Semibunch type & Cream white \& black \\
\hline 6 & 40 & S1 Sel 2 & Spreading type & Cream white with brown \&black spots \\
\hline 7 & 41 & AB 16-5C & Spreading type & Dark brown, black spots \\
\hline 8 & 42 & Caprivi Sel1 & Spreading type & Light brown with black spots \\
\hline 9 & 44 & SB8-1B & Semibunch type & Cream white \\
\hline 10 & 45 & S1 Sel 1 & Semibunch type & Light \& dark brown with black spots \\
\hline 11 & 46 & SB 14-7B & Semibunch type & Cream white \\
\hline 12 & 47 & SB 8-3C & Semibunch type & Cream white, black \& dark brown spots \\
\hline 13 & 48 & MV 40-38 & Semibunch type & Cream white, light \& dark brown spots \\
\hline 14 & 49 & MV 67-1 & Spreading type & Cream white \\
\hline 15 & 50 & MV 51-5-1C & Spreading type & Light brown \\
\hline 16 & 51 & MV 74-2 & Semibunch type & Light brown \\
\hline
\end{tabular}

\section{Selection and Preparation of Rhizobia Inoculants}

Four Bradyrhizobia strains viz. WB1, XBQ5, XS34, XBD2 and one Rhizobium strain (UD5), previously isolated from the root nodules of the legumes Glycine max L, Desmodium uncinatum, Arachis hypogaea, Cymopsis tetragonoloba and Phaseolus vulgaris respectively were obtained from the South African Rhizobium Culture Collection (SARCC) deposit. The bacteria were first revived from the frozen cultures stored at $-80^{\circ} \mathrm{C}$ and plated on Yeast Mannitol Congo Red (YMCR) Agar that contained ( $\left.\mathrm{g} \mathrm{L}^{-1}\right)$ : Mannitol (10), Yeast Extract (0.4), Dipotassium hydrogen phosphate $\left(\mathrm{K}_{2} \mathrm{HPO}_{4}\right)(0.5)$, Magnesium chloride $\left(7 \mathrm{H}_{2} \mathrm{O}\right.$ $\mathrm{MgCl})(0.2)$, Sodium chloride (0.1) and Agar (bacteriological) (15). The agar plates were incubated at $28^{\circ} \mathrm{C}$ for $3-7$ days based on their growth rate. A single pure colony of each of the rhizobium strain was inoculated into an Erlenmeyer flask containing $150 \mathrm{ml}$ sterile Yeast Mannitol (YM) Broth and incubated at 
$26^{\circ} \mathrm{C}$ for $36-48$ hours depending on their growth rate on a rotary shaker at $150 \mathrm{rpm}$. The concentration of the inoculum was adjusted to $10^{8} \mathrm{cfu} \mathrm{ml}^{-1}$ using viable plate count and spectrophotometric optical density measurement $\left(\mathrm{OD}_{600} \mathrm{~nm}=1.0-1.5\right)$.

\section{Glasshouse experimental layout and inoculation}

Bambara groundnut seeds were surface sterilized as described in Somasegaran and Hoben (1994). Briefly, seeds were covered in 1\% sodium hypochlorite for $1 \mathrm{~min}$. and $70 \%$ ethanol for $30 \mathrm{sec}$ after which they were rinsed in sterile distilled water for up to six times. The seeds were then covered with sterile water and incubated at $4^{\circ} \mathrm{C}$ for an overnight to imbibe. The imbibed seeds were transferred to a Leonard jar assembly (two seeds/Leonard jar) that contains sterile river sand and $\mathrm{N}$-free nutrient solution (Howieson and Dilworth 2016) composed of (g/L): $\mathrm{CaHPO}_{4}(1.0), \mathrm{MgSO}_{4} .7 \mathrm{H}_{2} \mathrm{O}(0.2), \mathrm{K}_{2} \mathrm{HPO}_{4}(0.2), \mathrm{NaCl}$ (0.2), $\mathrm{FeCl}_{3}(0.1)$, and trace elements solution $(1 \mathrm{ml} / \mathrm{L})$ made using the following chemicals $(\mathrm{g} / \mathrm{L}): \mathrm{H}_{3} \mathrm{BO}_{3}$ (2.86), $\mathrm{MnSO}_{4} \cdot 4 \mathrm{H}_{2} \mathrm{O}$ (2.03), $\mathrm{ZnSO}_{4} .7 \mathrm{H}_{2} \mathrm{O}(0.22), \mathrm{CuSO}_{4} .5 \mathrm{H}_{2} \mathrm{O}(0.08), \mathrm{Na}_{2} \mathrm{MoO}_{4} .2 \mathrm{H}_{2} \mathrm{O}$ (0.14). There were 16 landraces (genotypes) of $V$. subterranea (L.) Verdc. which were inoculated with each of the five bacterial strains in three replications in the glasshouse trial. Two $\mathrm{ml}$ of each of the inoculants prepared as above were applied to each seed in the Leonard jar and the seeds were gently covered with the sand immediately after inoculation. The experiment was arranged in a completely randomized design (CRD) and the plants were monitored for six weeks before harvesting and evaluation. The experiment was repeated twice and data were compiled as the average of the two trials for evaluation and selection.

\section{Statistical Analysis}

The data collected were total fresh weight, total dry weight and nodule number, which were then subjected to an analysis of variance (ANOVA) using the general linear models procedure (PROC GLM) in SAS version 9.4 statistical software (SAS 2016). The comparison of the means with significant effects was analysed using Fisher's protected t-Least Significant Differences (LSD's) at ( $a=0.05)$. Multivariate analysis such as Principal component analysis (PCA) and agglomerative hierarchical clustering using XLSTAT (Addinsoft 2016) software were conducted to visualise and elucidate the relationships between the treatments and their attributes.

\section{Bacterial Identification using 16S rRNA genotyping}

The rhizobia isolates used in this study were previously characterized preliminary to the Genus level based solely on their growth rate as well as their cultural and microscopic properties. We therefore conducted the $16 \mathrm{~S}$ ribosomal RNA based method of identification to elucidate the actual taxonomic and/or phylogenetic positions of the rhizobia. All bacteria were grown in an Erlenmeyer flask containing $100 \mathrm{ml}$ Tryptone Yeast Extract (TY) broth for 24 - 48 hours at $28^{\circ} \mathrm{C}$ with continuous shaking at $150 \mathrm{rpm}$. The resulting culture suspension $(2 \mathrm{ml})$ was used to extract genomic DNA using the WIZARD® Genomic DNA Purification kit following the manufacturer's instruction (Promega, Maddison, WI, USA). Before conducting the polymerase chain reaction (PCR), we quantified the DNA by measuring the absorbance of light at $260 \mathrm{~nm}$ using spectrophotometer, after which about $5 \mu$ l of this DNA was used as a template for 
the PCR reaction. Oligonucleotide primers used were fD1 (5' AGAGTTTGATCCTGGCTCAG 3') and rD1 (5'AAGGAGGTGATCCAGCC 3') corresponding to positions 27 and 1524-1540 of E. coli numbering of 16S ribosomal RNA sequence (Weisburg et al. 1991). The purified PCR products were sent to Inqaba Biotech (South Africa) for sequencing. Sequences received from Inqaba Biotech were edited using Bioedit and Chromas Lite programs. The consensus sequences were used to query the NCBI database with a BLASTn search at https://blast.ncbi.nIm.nih.gov/Blast.cgi and on the EzBioCloud server https://www.ezbiocloud.net. (Yoon et al. 2017). The sequences were aligned with reference sequences obtained from the NCBI database using online sequence alignment program (MAFFT) (Katoh et al. 2002) to construct Maximum Likelihood (ML) phylogenetic tree using the Tamura-Nei statistical model and a test of phylogeny with 1000 bootstrap replications on MEGA X (Kumar et al. 2018). Sequences were deposited at the NCBI GenBank library with accession numbers from MZ149921 - MZ149925.

\section{Results}

\section{Glasshouse nodulation compatibility screening}

There exists a significant variation in the response of the 16 landraces of bambara groundnut and five rhizobia strains in terms of the formation of nodules, but there was no significant interaction. Moreover, significant variation was also observed for the shoot fresh weight and dry weight across the landraces but not with rhe rhizobia strains (Table 1). Of the five rhizobia strains tested in this screening, rhizobium strain XBD2 showed the most compatibility with bambara landraces \#34, 35, 38, 42 and 45 by inducing the formation of between 10 - 20 nodules per plant. Following rhizobium strain XBD2, the highest symbiotic compatibility with the bambara landraces in terms of inducing the process of nodulation was achieved by rhizobium strain XS34 that formed 18 and 12 nodules per plant with bambara cultivars \#34 and \# 49 respectively. The number of nodules formed between these two rhizobium strains (XBD2 and XS34) and the above-mentioned landraces is statistically $(p=0.05)$ significant compared to the interactions made with the rest of the rhizobium strains and any of the bambara groundnut genotypes. The nodules formed by strains XBD2 and XS34 on the roots of the specific bambara groundnut landraces to which they are highly compatible were very conspicuous and pink indicating the potential for active nitrogen fixation (Figure 1). However, due to the main objective of the current study being the screening and comparison of the 16 landraces of bambara groundnut for nodulation compatibility and specificity with the five rhizobia species, nitrogen fixation assays were not conducted and thus, data for $\mathrm{N}$-content and $\mathrm{N}_{2}$-fixation measurement are not included. The lowest nodulation compatibility with most of the bambara landraces was observed for the rhizobium strains UD5 and XBQ5 followed by strain WB1. These rhizobia strains either resulted in the formation of no nodules or only formed $\leq 5$ nodules/plant. 
Table 2

Level of significance $(\mathrm{Pr}>\mathrm{F})$ at $\mathrm{p}=0.05$ of the interactions between five rhizobia strains and 16 bambara groundnut landraces for nodule formation, dry weight and fresh weight in a glasshouse nodulation and growth promotion assay

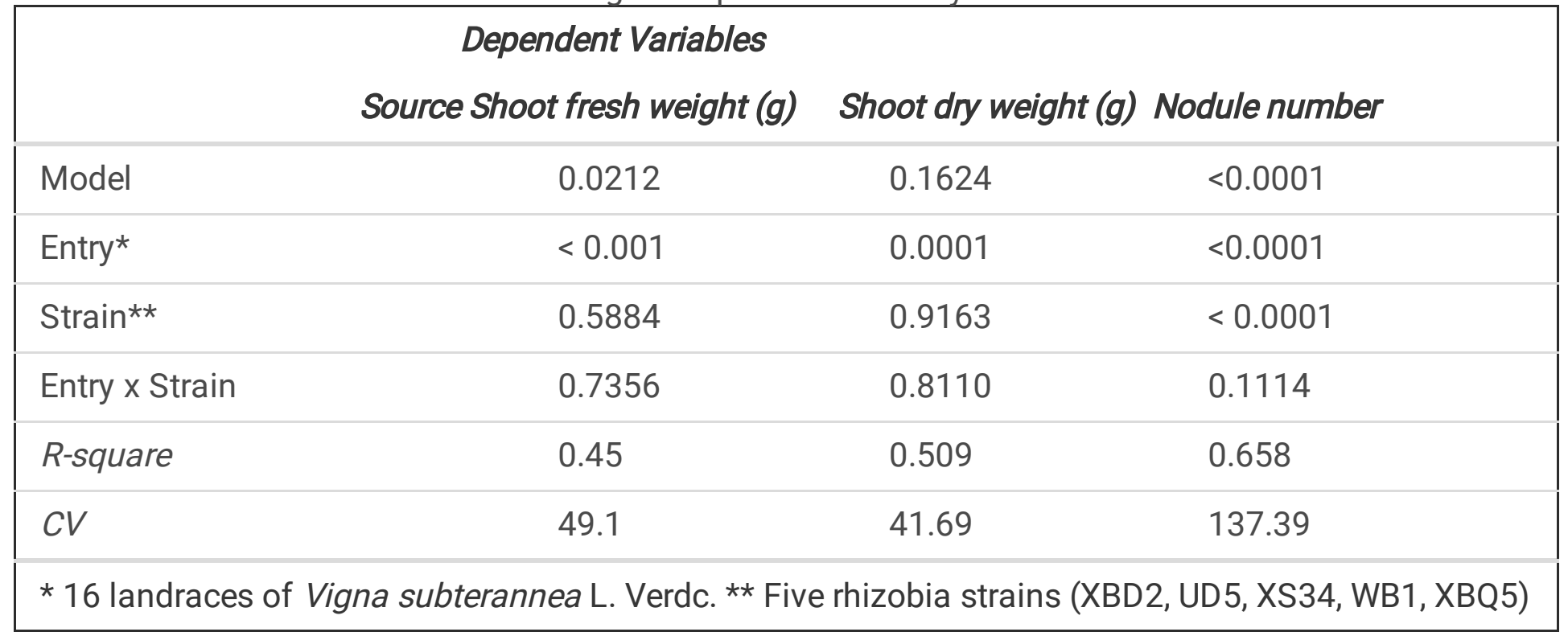

Table 3 Least significance difference (LSD) $t$ test to evaluate the interaction between five rhizobia strains ${ }^{\dagger}$ and 16 Vigna subterranea L. landrace collections in terms of nodule number, total fresh weight and total dry weight per plant in a glasshouse inoculation trial 


\begin{tabular}{|c|c|c|c|c|}
\hline No & Entry_Strain* & Nodule number/plant & Total Fresh weight $(g)$ & $\begin{array}{l}\text { Total dry weight } \\
\text { (g) }\end{array}$ \\
\hline 1 & 34_UD5 & $4.50 \pm 3.67^{f-n^{*}}$ & $5.78 \pm 0.13^{a-h^{*}}$ & $1.09 \pm 0.06^{a-f^{*}}$ \\
\hline 2 & 34_XBQ5 & $9.17 \pm 0.00^{c-j}$ & $4.65 \pm 1.31^{\mathrm{a}-\mathrm{I}}$ & $0.61 \pm 0.18^{a-1}$ \\
\hline 3 & 34_WB1 & $8.00 \pm 0.00^{\mathrm{d}-\mathrm{m}}$ & $3.83 \pm 0.00^{b-1}$ & $0.74 \pm 0.00^{a-1}$ \\
\hline 4 & 34_XBD2 & $17.00 \pm 0.00^{\mathrm{abc}}$ & $3.88 \pm 0.00^{\mathrm{b}-\mathrm{I}}$ & $0.61 \pm 0.00^{c-1}$ \\
\hline 5 & 34_XS34 & $18.00 \pm 0.00^{\mathrm{ab}}$ & $6.08 \pm 0.00^{a-f}$ & $1.02 \pm 0.00^{a-i}$ \\
\hline 6 & 34_Control & $0.00 \pm 0.00^{n}$ & $3.76 \pm 0.00^{b-1}$ & $0.97 \pm 0.00^{\mathrm{a}-\mathrm{j}}$ \\
\hline 7 & 35_XBD2 & $20.00 \pm 0.52^{\mathrm{a}}$ & $6.52 \pm 2.75^{\mathrm{a}-\mathrm{d}}$ & $0.94 \pm 0.22^{\mathrm{a}-\mathrm{j}}$ \\
\hline 8 & 35_Control & $0.00 \pm 0.00^{n}$ & $5.58 \pm 0.31^{a-k}$ & $1.08 \pm 0.16^{a-g}$ \\
\hline 9 & 35_UD5 & $1.41 \pm 0.81^{I m n}$ & $5.75 \pm 0.32^{a-i}$ & $1.08 \pm 0.08^{a-g}$ \\
\hline 10 & 35_WB1 & $10.00 \pm 6.4^{\mathrm{c}-\mathrm{h}}$ & $5.73 \pm 0.55^{a-j}$ & $0.89 \pm 0.13^{a-k}$ \\
\hline 11 & 35_XBQ5 & $20.00 \pm 5.16^{e-n}$ & $6.83 \pm 0.39^{a b}$ & $0.94 \pm 0.09 a b c$ \\
\hline 12 & 35_XS34 & $9.50 \pm 4.76^{\mathrm{c}-\mathrm{i}}$ & $5.12 \pm 0.77^{a-l}$ & $0.84 \pm 0.29 a-1$ \\
\hline 13 & 36_Control & $0.00 \pm 0.00^{n}$ & $2.20 \pm 0.00^{\prime}$ & $0.36 \pm 0.00^{h-1}$ \\
\hline 14 & 36_UD5 & $0.00 \pm 0.00^{n}$ & $3.38 \pm 0.00^{c-1}$ & $0.51 \pm 0.00^{d-I}$ \\
\hline 15 & 36_WB1 & $2.00 \pm 0.00^{i-n}$ & $3.81 \pm 0.00^{b-1}$ & $0.65 \pm 0.00^{b-1}$ \\
\hline 16 & 36_XBD2 & $1.50 \pm 1.22^{j-n}$ & $2.46 \pm 1.02^{\mathrm{k}-\mathrm{l}}$ & $0.41 \pm 0.19^{\mathrm{f}-\mathrm{I}}$ \\
\hline 17 & 36_XBQ5 & $0.00 \pm 0.00^{n}$ & $2.01 \pm 0.00^{\prime}$ & $0.34 \pm 0.00^{\mathrm{ijkl}}$ \\
\hline 18 & 37_Control & $0.00 \pm 0.00^{n}$ & $6.48 \pm 0.12^{\mathrm{abcd}}$ & $1.37 \pm 0.05^{a}$ \\
\hline 19 & 37_UD5 & $0.67 \pm 0.66^{1 \mathrm{mn}}$ & $5.62 \pm 0.94^{a-k}$ & $0.97 \pm 0.23^{a-j}$ \\
\hline 20 & 37_WB1 & $1.33 \pm 0.88^{-n}$ & $5.98 \pm 0.13^{a-g}$ & $0.97 \pm 0.099^{a-j}$ \\
\hline 21 & 37_XBD2 & $1.00 \pm 0.99^{\mathrm{Imn}}$ & $2.99 \pm 1.92^{\mathrm{e}-\mathrm{I}}$ & $0.57 \pm 0.28^{d-1}$ \\
\hline 22 & 37_XBQ5 & $0.00 \pm 0.00^{n}$ & $5.75 \pm 2.14^{\mathrm{a}-\mathrm{h}}$ & $1.16 \pm 0.49 \mathrm{abcd}$ \\
\hline 23 & 37_XS34 & $4.33 \pm 2.33^{f-n}$ & $7.19 \pm 1.09^{a}$ & $1.31 \pm 0.05^{a b}$ \\
\hline
\end{tabular}




\begin{tabular}{|c|c|c|c|c|}
\hline 24 & 38_Control & $0.00 \pm 0.00^{n}$ & $2.88 \pm 0.53^{f-1}$ & $0.23 \pm 0.23 \mathrm{kl}$ \\
\hline 25 & 38_UD5 & $5.50 \pm 2.85^{\mathrm{e}-\mathrm{n}}$ & $3.88 \pm 0.07^{b-1}$ & $0.71 \pm 0.58^{a-l}$ \\
\hline 26 & 38_XBQ5 & $0.00 \pm 0.00^{n}$ & $4.81 \pm 0.37^{a-1}$ & $0.90 \pm 0.16^{a-k}$ \\
\hline 27 & 38_XBD2 & $12.00 \pm 5.71^{b-f}$ & $3.31 \pm 0.09^{d-I}$ & $0.53 \pm 0.03^{d-1}$ \\
\hline 28 & 38-WB1 & $2.00 \pm 1.63^{e-n}$ & $4.10 \pm 0.19 a-I$ & $0.82 \pm 0.07^{a-1}$ \\
\hline 29 & 38_XS34 & $2.67 \pm 2.17^{h-n}$ & $2.52 \pm 1.40^{\mathrm{jkl}}$ & $0.47 \pm 0.26^{\mathrm{e}-\mathrm{I}}$ \\
\hline 30 & 40_Control & $0.00 \pm 0.00^{n}$ & $4.55 \pm 0.39^{a-I}$ & $0.89 \pm 0.10^{a-k}$ \\
\hline 31 & 40_UD5 & $0.00 \pm 0.00^{n}$ & $2.61 \pm 0.77^{h-1}$ & $0.47 \pm 0.19^{\mathrm{e}-\mathrm{I}}$ \\
\hline 32 & 40_WB1 & $0.00 \pm 0.00^{n}$ & $5.10 \pm 1.14 a-I$ & $0.91 \pm 0.15^{a-k}$ \\
\hline 33 & 40_XBD2 & $6.83 \pm 3.75^{d-n}$ & $3.38 \pm 0.45^{c-1}$ & $0.16 \pm 0.09^{b-1}$ \\
\hline 34 & 40_XBQ5 & $1.50 \pm 1.22^{j-n}$ & $4.48 \pm 0.69^{a-1}$ & $0.93 \pm 0.14^{a-j}$ \\
\hline 35 & 40_XS34 & $0.00 \pm 0.00^{n}$ & $4.03 \pm 0.04 a-1$ & $0.73 \pm 0.04^{a-1}$ \\
\hline 36 & 41_Control & $0.00 \pm 0.00^{n}$ & $2.47 \pm 0.41^{\mathrm{kl}}$ & $0.17 \pm 0.13^{\prime}$ \\
\hline 37 & 41_UD5 & $0.00 \pm 0.00^{n}$ & $2.68 \pm 0.57^{h-l}$ & $0.58 \pm 0.07^{d-l}$ \\
\hline 38 & 41_WB1 & $0.00 \pm 0.00^{n}$ & $3.62 \pm 1.22 b-1$ & $0.67 \pm 0.38^{d-1}$ \\
\hline 39 & 41_XBD2 & $3.17 \pm 2.45^{g-n}$ & $5.06 \pm 2.36^{\mathrm{a}-\mathrm{I}}$ & $0.85 \pm 0.43^{a-1}$ \\
\hline 40 & 41_XBQ5 & $0.00 \pm 0.00^{n}$ & $2.35 \pm 0.66$ & $0.42 \pm 0.13^{f-I}$ \\
\hline 41 & 41_XS34 & $0.00 \pm 0.00^{n}$ & $4.36 \pm 0.60 a-1$ & $0.68 \pm 0.01^{b-1}$ \\
\hline 42 & 42_Control & $0.00 \pm 0.00^{n}$ & $2.61 \pm 1.08^{h-1}$ & $0.47 \pm 0.20^{\mathrm{e}-\mathrm{I}}$ \\
\hline 43 & 42_UD5 & $0.33 \pm 0.31^{\mathrm{mn}}$ & $4.17 \pm 1.20 \mathrm{a}-\mathrm{I}$ & $0.95 \pm 0.24^{a-j}$ \\
\hline 44 & 42_WB1 & $0.00 \pm 0.00^{n}$ & $5.57 \pm 1.39 a-k$ & $1.04 \pm 0.21^{a-h}$ \\
\hline 45 & 42_XBD2 & $11.0 \pm 5.03^{b-f}$ & $4.26 \pm 0.54 a-1$ & $0.75 \pm 0.09^{a-1}$ \\
\hline 46 & 42_XBQ5 & $0.00 \pm 0.00^{n}$ & $3.15 \pm 0.29^{\mathrm{e}-\mathrm{I}}$ & $0.67 \pm 0.10^{b-1}$ \\
\hline 47 & 42_XS34 & $0.33 \pm 0.33^{\mathrm{mn}}$ & $4.96 \pm 0.13 a-I$ & $0.96 \pm 0.01^{a-j}$ \\
\hline 48 & 44_Control & $0.00 \pm 0.00^{n}$ & $2.48 \pm 0.16^{\mathrm{kl}}$ & $0.54 \pm 0.18^{d-l}$ \\
\hline 49 & 44_UD5 & $0.00 \pm 0.00^{n}$ & $3.39 \pm 0.18 c-1$ & $0.62 \pm 0.05^{b-1}$ \\
\hline
\end{tabular}




\begin{tabular}{|c|c|c|c|c|}
\hline 50 & 44_WB1 & $0.00 \pm 0.00^{n}$ & $2.82 \pm 0.73^{g-1}$ & $0.55 \pm 0.14^{d-I}$ \\
\hline 51 & 44_XBD2 & $5.00 \pm 4.08 e-n$ & $2.82 \pm 0.38^{g-1}$ & $0.48 \pm 0.19 \mathrm{~d}-1$ \\
\hline 52 & 44_XBQ5 & $0.00 \pm 0.00 n$ & $3.20 \pm 0.01^{\mathrm{e}-\mathrm{I}}$ & $0.75 \pm 0.08^{a-1}$ \\
\hline 53 & 44_XS34 & $2.33 \pm 2.33^{h-n}$ & $3.11 \pm 0.42^{\mathrm{e}-\mathrm{I}}$ & $0.64 \pm 0.13^{b-1}$ \\
\hline 54 & 45_Control & $0.00 \pm 0.00^{n}$ & $3.41 \pm 0.46 c-1$ & $0.61 \pm 0.08^{c-1}$ \\
\hline 55 & 45_UD5 & $3.50 \pm 1.76^{g-n}$ & $2.34 \pm 0.05^{\prime}$ & $0.33 \pm 0.13^{i j k l}$ \\
\hline 56 & 45_WB1 & $2.50 \pm 0.28^{h-n}$ & $2.52 \pm 0.21^{\mathrm{jkl}}$ & $0.42 \pm 0.04^{\mathrm{f}-\mathrm{I}}$ \\
\hline 57 & 45_XBD2 & $13.5 \pm 3.67^{\mathrm{abcd}}$ & $3.82 \pm 0.31 \mathrm{~b}-\mathrm{I}$ & $0.62 \pm 0.03^{b-1}$ \\
\hline 58 & 45_XS34 & $6.00 \pm 4.89^{d-n}$ & $2.52 \pm 0.71^{\mathrm{jkl}}$ & $0.39 \pm 0.13^{g-1}$ \\
\hline 59 & 46_Control & $0.00 \pm 0.00^{n}$ & $3.25 \pm 0.56^{\mathrm{e}-\mathrm{I}}$ & $0.71 \pm 0.24^{a-1}$ \\
\hline 60 & 46_XS34 & $3.33 \pm 1.66^{h-n}$ & $3.83 \pm 0.34^{\mathrm{b}-\mathrm{I}}$ & $0.67 \pm 0.05^{b-1}$ \\
\hline 61 & 46_UD5 & $1.17 \pm 1.66^{\mathrm{klmn}}$ & $3.25 \pm 0.39^{\mathrm{e}-\mathrm{I}}$ & $0.09 \pm 0.05^{\mathrm{d}-\mathrm{I}}$ \\
\hline 62 & 46_WB1 & $2.33 \pm 1.29^{h-n}$ & $2.98 \pm 0.64^{\mathrm{e}-\mathrm{I}}$ & $0.23 \pm 0.13^{\mathrm{d}-\mathrm{I}}$ \\
\hline 63 & $\begin{array}{l}\text { 46_XBD2 } \\
46 \times \mathrm{XBO5}\end{array}$ & $8.33 \pm 1.58^{\mathrm{e}-1}$ & $4.70 \pm 1.89^{a-1}$ & $0.67 \pm 0.38^{a-1}$ \\
\hline \multirow[t]{2}{*}{65} & 47_Control & $10.16 \pm 4.34^{\mathrm{b}-\mathrm{h}}$ & $3.89 \pm 0.12^{\mathrm{b}-\mathrm{I}}$ & $0.77 \pm 0.12^{a-1}$ \\
\hline & & $0.00 \pm 0.00^{n}$ & $2.53 \pm 0.41^{\mathrm{jkl}}$ & $0.43 \pm 0.01^{\mathrm{f}-\mathrm{I}}$ \\
\hline 66 & 47_UD5 & $0.00 \pm 0.00^{n}$ & $2.56 \pm 0.45^{\mathrm{ijkl}}$ & $0.83 \pm 0.44^{a-1}$ \\
\hline 67 & 47_XBD2 & $0.00 \pm 0.00^{n}$ & $2.70 \pm 0.00^{\mathrm{h}-\mathrm{I}}$ & $0.52 \pm 0.00^{d-I}$ \\
\hline 68 & 48_UD5 & $0.00 \pm 0.00^{n}$ & $2.29 \pm 0.00^{\prime}$ & $0.03 \pm 0.00^{\mathrm{jkl}}$ \\
\hline 69 & 48_WB1 & $0.00 \pm 0.00^{n}$ & $6.16 \pm 1.25^{\mathrm{a}-\mathrm{e}}$ & $1.13 \pm 0.32^{a-e}$ \\
\hline 70 & 48_XBD2 & $2.00 \pm 1.63^{i-n}$ & $2.77 \pm 019^{a-l}$ & $0.49 \pm 0.03^{d-1}$ \\
\hline 71 & 48_XBQ5 & $0.00 \pm 0.00^{n}$ & $3.19 \pm 0.18^{\mathrm{e}-\mathrm{I}}$ & $0.38 \pm 0.19^{h-1}$ \\
\hline 72 & 48_XS34 & $0.00 \pm 0.00^{n}$ & $3.19 \pm 1.29^{\mathrm{e}-\mathrm{I}}$ & $0.64 \pm 0.23^{b-1}$ \\
\hline 73 & 49_Control & $0.00 \pm 0.00^{n}$ & $4.49 \pm 2.76^{\mathrm{a}-\mathrm{I}}$ & $1.01 \pm 0.87^{a-i}$ \\
\hline 74 & 49_UD5 & $0.25 \pm 0.17^{\mathrm{mn}}$ & $2.25 \pm 1.01^{\prime}$ & $0.44 \pm 0.24^{\mathrm{f}-\mathrm{I}}$ \\
\hline
\end{tabular}




\begin{tabular}{|c|c|c|c|c|}
\hline 75 & 49_WB1 & $0.00 \pm 0.00^{n}$ & $3.72 \pm 0.00^{\mathrm{b}-1}$ & $0.74 \pm 0.00^{a-1}$ \\
\hline 76 & 49XBD2 & $2.33 \pm 1.20^{\mathrm{h}-\mathrm{n}}$ & $4.71 \pm 1.20^{\mathrm{a}-\mathrm{I}}$ & $0.70 \pm 0.41^{a-l}$ \\
\hline 77 & 49_XBQ5 & $6.00 \pm 0.00 d-n$ & $6.53 \pm 2.01^{\mathrm{abc}}$ & $0.75 \pm 0.02^{\mathrm{a}-1}$ \\
\hline 78 & 49_XS34 & $12.50 \pm 2.85 \mathrm{a}-\mathrm{e}$ & $3.25 \pm 1.58^{\mathrm{e}-\mathrm{I}}$ & $0.86 \pm 0.27^{a-k}$ \\
\hline 79 & 50_Control & $0.00 \pm 0.00 n$ & $3.18+1.24^{\mathrm{e}-\mathrm{I}}$ & $0.86+0.07^{a-k}$ \\
\hline 80 & 50_UD5 & $4.25 \pm 1.02 f-n$ & & \\
\hline 81 & 50_WB1 & $0.00 \pm 0.00 n$ & $4.59 \pm 0.21^{a-1}$ & $0.89 \pm 0.08^{a-k}$ \\
\hline 82 & 50_XBD2 & $9.00 \pm 5.06^{d-k}$ & $2.78 \pm 0.66^{\mathrm{g}-1}$ & $0.43 \pm 0.08^{f-l}$ \\
\hline 83 & 50_XBQ5 & $0.50 \pm 0.491 \mathrm{mn}$ & $5.09 \pm 0.54^{\mathrm{a}-1}$ & $0.92 \pm 0.07^{a-k}$ \\
\hline \multirow[t]{2}{*}{84} & 50_XS34 & $5.33 \pm 4.60^{\mathrm{e}-\mathrm{n}}$ & $4.62 \pm 0.59^{a-1}$ & $0.90 \pm 0.10^{a-k}$ \\
\hline & & & $4.01 \pm 0.77^{a-1}$ & $0.77 \pm 0.03^{a-1}$ \\
\hline & $(L S D) t_{p=0.05}$ & 7.940 & 1.3504 & 0.6925 \\
\hline \multicolumn{5}{|c|}{$P R>F$} \\
\hline & Model & $<0.001$ & 0.021 & \multirow{2}{*}{$\begin{array}{l}0.1624 \\
0.8110\end{array}$} \\
\hline & Entry & 0.1114 & 0.735 & \\
\hline
\end{tabular}

*In each column, values (mean $\pm \mathrm{SE}$ ) followed by the same letters are not significantly different at $p=0.05$ according to the LSDt test.

A principal component analysis (PCA) was performed in order to identify the differences/association between the entry strains and plant growth parameters. The first principal component contributed $65.64 \%$ of genetic variation, which was dominated by the number of nodules. The entry-strain interactions concentrated in the first quadrant showed high number of nodules. The entry strain associations found in the fourth quadrant were associated with high fresh and dry mass weight. In contrast, the entry-strain interactions which were concentrated in the second and third quadrants scored lowest amount of growth parameters recorded indicating that they genetically diverse among each other. The biplot had a discriminating power of the entry strain associations (Table 3; Figure 2A). Hence, results from the principal component analysis biplot revealed that the number of nodules per plant formed in the symbiotic interaction between cultivar \#34 and XS34, 34 and XBD2 as well as that between cultivar 35 and strain XBD2 have higher positive scores /associations on both principal coordinates (Figure 2A). In general, correlational analysis using PCA indicates a positive correlation between fresh weight and dry weight, however no correlation exists between nodule number and plant biomass (Table 3, Figures 2A, 2B). From the dissimilarity cluster analysis, it was very clear that the $16 \mathrm{~V}$. subterranea landraces 
responded very differently to the inoculation of the six rhizobia strains in terms of nodule formation. The hierarchical graph clearly indicates that based on their nodulation compatibility there were three major clusters and six sub-clusters. The clusters with the most compatible rhizobia strains and their $V$. subterranean landraces are grouped together which includes Bradyrhizobium strain XBD2 and landraces $34,35,38,40,42,45,46,49$, and 50 . On the other hand, the controls and other non or low nodulating combinations were quite well distributed among two of the three main clusters (Figure 3 ).

\section{Phylogenetic characterization of rhizobia}

The consensus sequences generated from the forward and reverse sequences of the 16S ribosomal RNA of the five rhizobia strains were used to run a BLASTn search made on both the NCBI database library as well as on Ezbiocloud server. Table 3 represents the percentage similarity and the taxonomic position (species ID) of the five rhizobia strains based on the $16 \mathrm{~S}$ ribosomal RNA sequence analysis. Selected reference sequences of the 16S rRNA for the type strains of rhizobia from the NCBI and/or Ezbiocloud server that resulted in the highest nucleotide similarity (98-100\%) were aligned to construct the Maximum Likelihood (ML) phylogenetic tree. Bootstrapping based on 1000 replications in the construction of the phylogenetic tree resulted in the placement of the five rhizobia strains into four major distinct clades. All the five rhizobia strains were placed in a separate clade of their own. The two rhizobia strains, XBD2 and XS34, which showed the highest nodulation compatibility with several of the landraces formed, are phylogenetically different having their own unique clade with in the tree. Interestingly, strain XBD2 originally isolated from Cyamopsis tetragonoloba (a cowpea miscellany group), showed more evolutionary divergence with unique mutations not found in all the strains used in the phylogenetic construction (Figure 4). To the contrary, XS34 seems to be less divergent having very similar sequences with several Bradyrhizobium species. Strain UD5, isolated from Phaseolus sp., a non-cowpea miscellany group, has been identified as Rhizobium tropici and grouped in the top part of the phylogenetic tree with Rhizobium type strains. 
Table 4

Rhizobia spp. used in the nodulation compatibility screening with 16 landraces of bambara groundnut (Vigna subterranea (L.) Verdc. and their taxonomic position (species ID) based on the 16S ribosomal RNA sequence similarity search using blastn tool on both the $\mathrm{NCBI}$ and EzBiocloud databases libraries

\begin{tabular}{|c|c|c|c|c|c|c|}
\hline \multirow{2}{*}{$\begin{array}{l}\text { Rhizobia } \\
\text { strain }\end{array}$} & \multirow{2}{*}{$\begin{array}{l}\text { SARCC* } \\
\text { code }\end{array}$} & \multirow{2}{*}{$\begin{array}{l}\text { Original } \\
\text { legume host }\end{array}$} & \multicolumn{4}{|c|}{ BLAST similarity search results (\%) } \\
\hline & & & NCBI server & & EzBioCloud server & \\
\hline XBQ5 & $\begin{array}{l}\text { SARCC- } \\
401\end{array}$ & $\begin{array}{l}\text { Desmodium } \\
\text { uncinatum }\end{array}$ & $\begin{array}{l}\text { Bradyrhizobium } \\
\text { elkani }\end{array}$ & $100 \%$ & $\begin{array}{l}\text { Bradyrhizobium } \\
\text { sp. }\end{array}$ & $94 \%$ \\
\hline XBD2 & $\begin{array}{l}\text { SARCC- } \\
388\end{array}$ & C. tetragonoloba & B. zhangangense & $100 \%$ & B.zhangangense & $100 \%$ \\
\hline XS34 & $\begin{array}{l}\text { SARCC- } \\
578\end{array}$ & hypogaea & B. centrosematis & $100 \%$ & B. centrosematis & $100 \%$ \\
\hline UD5 & $\begin{array}{l}\text { SARCC- } \\
715\end{array}$ & vulgaris & Rhizobium tropici & $98.1 \%$ & $\begin{array}{l}\text { R. tropici } \\
\text { HFBPRD2 }\end{array}$ & $98.9 \%$ \\
\hline WB1 & $\begin{array}{l}\text { SARCC- } \\
304\end{array}$ & & B. elkani & $100 \%$ & B. elkani 5170D & $100 \%$ \\
\hline
\end{tabular}

\section{Discussion And Conclusion}

A screening trial for the ability of five rhizobia strains to form nodules and improve plant growth promotion in terms of biomass increase has been tested across 16 landrace collections of bambara groundnut (Vigna subterranea L.Verdc). None of the rhizobia strains tested in this nodulation compatibility test is the natural microsymbionts for bambara, but were isolated from the nodules of other legumes including common bean (Phaseolus vulgais), silverleaf desmodium (Desmodium uncinatum), soy bean (Glycine max), peanut (Arachis hypogaea) and cluster bean (Cyamopsis tetragololoba). Three of these legumes, with the exception of soybean and common bean, belong to the same cross inoculation group with bambara groundnut, and thus the selection of these rhizobia for this screening study was based on the assumption $V$. subterranea $L$. Verdc. could be nodulated by rhizobia isolated from legumes within its cross inoculation group. Moreover, there is lack of sufficient information on the symbiotic interaction or on the promiscuous behavior of $V$. subterranea $L$. to nodulate with other rhizobia within or outside of the cross inoculation group of this legume.

A major limitation of most research on underutilized crops such as bambara groundnut is that, it is confined to a single aspect such as breeding of a particular species or landraces. Research on breeding of resistant varieties of a given legume species is very essential. However, the commonly observed gap in these research findings is that breeding for the selection of resistant or high yield variety legumes is not usually accompanied by nodulation and nitrogen fixation compatibility between a given genotype and a specific rhizobium strain (Masson-Bovin and Sachs 2018). Moreover, many of the farmers in sub Saharan Africa regions obtain seeds from local landraces rather than varieties bred specifically for 
particular production system and agro ecological conditions. It is also observed in several studies that no matter how a high yielding variety of legume is developed through breeding, rhizobium inoculation for improved nitrogen fixation might fail due to poor compatibility and nodulation competitiveness, or nonspecificity of the rhizobia to the host legume (Sar et al. 2009).

Bambara groundnut is typically a tropical legume that nodulates with cowpea type Bradyrhizobia. At the very early stage of the legume-rhizobium symbiotic study, Doku (1969) demonstrated the ability of bambara groundnut to cross nodulate with isolates from different tropical legumes, which indicated the species is less selective in its rhizobium requirement. Studies that involve the nodulation compatibility screening are very important in the selection of effective nitrogen fixing strains of rhizobia for a given landrace (genotype) of bambara groundnut. This concept is contrary to the early opinion or suggestion that bambara groundnut does not require nodulation with rhizobia (Johnson 1968). However, it has been experimentally proven that inoculating bambara groundnut with suitable strains of Bradyrhizobium sp. can increase yields in which the increase in the symbiotic performance and grain yield was higher after inoculation with indigenous Bradyrhizobium sp. (Dakora and Muofhe 1995).

Host microbe specificity is observed in many legumes and is one of the important factors that affect the distribution of indigenous rhizobia. It is also possible that the distribution of indigenous rhizobia is affected by the type of legume crop (Sar et al. 2009). In the current study, although there was very little statistically significant difference between the majority of the bambara ground genotypes and the rhizobium strains, nodulation was induced by almost all the rhizobium strains with no sign of legumerhizobium host specificity. The lack of such host specificity of the bambara groundnut genotypes to unique root nodulating genera of rhizobia complex has been reported previously (Grönmeyer et al.2016). According to this report, at least three species of bacteria (Bradyrhizobium, Burkholderia and rhizobium spp.) were associated with the nodulation of $V$. subterranea that supports the results found in the current study. As per the report by Guar and Sen (1979), all Bradyrhizobium isolates that induced nodulation on cowpea also nodulated bambara groundnut which however did not induce any nodule formation on common bean.

Interestingly in the current study, despite the variation in the symbiotic performances, the rhizobia isolates from Arachis hypogaea, Desmodium uncinatum, Cyamopsis tetragonoloba, all formed effective, pink nodules on $V$. subterranea $L$. Verdc. after inoculation. The least symbiotic performance and compatibility with the bambara landraces was exhibited by Rhizobium strain UD5, the microsymbiont of Phaseolus vulgaris L. and Bradyrhizobium strain WB1 a symbiont of soybean. Comparatively, the other three Rhizobia strains XBD2, XS34 and XBQ5 showed more compatibility by inducing the formation of up to 20 nodules per plant. This could definitely not be an occurrence by chance, but due to the fact that these rhizobia were originally isolated from the nodules of cluster bean or guar (Cymospsis tetragonoloba), groundnut (Arachis hypogaea) and Desmodium uncinatum, all of which also belong to the cowpea miscellany cross inoculation group (Guar and Sen 1979). In an elaborated review on the nodulation properties of African legumes, Sprent et al. (2010) described that Vigna subterranea is analogous to the distantly related Arachis hypoaea as both form underground seeds. This could probably be another 
explanation for the occurrence of significant nodulation compatibility between the $V$. subterranea land races and rhizobium strain XS34, originally isolated from Arachis hypogaea, and now identified as Bradyrhizobium centrosematis. On the other hand, the variation observed in the nodulation compatibility between the bambara landraces and the rhizobia strains is also expected due to the genetic variations that exists among the land races. Such cultivar variation in nodulation and nitrogen fixation efficiency has been demonstrated in several legumes studied to date including clover, soybean, common bean and alfalfa. The variations arise due to differences in a range of traits associated with nitrogen fixation including nodule number, biomass, as well as speed of nodulation (Graham et al. 2004). Despite its promiscuous nature, the existence of a marked difference in symbiotic variability of bambara groundnut cultivars and Bradyrhizobium spp. has also been demonstrated in earlier studies (Somasegaran et al.1989). The significant increase observed in the number of nodules (Table 2) as well as nodule size and color (data not shown) among the different landraces of $V$. subteranea in response to rhizobia inoculation are essential, as they indicate the potential for improved nitrogen fixation (Bennett et al. 2013). Such variation in the number of nodules formed in response to rhizobia and the associated variation in nitrogen fixation is also observed as a common characteristics in natural populations of legume species (Elliot et al. 2009).

It is generally believed that many African soils contain a diverse group of indigenous populations of Bradyrhizobia spp. that can nodulate and fix atmospheric nitrogen in several legumes. Recently, Pouzaa (2017) demonstrated that based on the 16S rRNA phylogenetic analysis, three different species of Bradyrhizobim including $B$. vignae, $B$. kavangense and $B$. elkani nodulated bambara groundnut. $B$. vignae has also been reported to nodulate other legumes such as $V$. unguiculata, Arachis hypogaea and Lablab purpureus (Grönmeyer et al. 2014). In the current study, according to the 16S ribosomal RNA analysis using the Maximum Likelihood (ML) phylogenetic tree, the five rhizobia strains were placed into four different phylogenetic clades (Figure 4). The strains, which were originally isolated from the cowpea miscellany cross inoculation groups (XBD2, XS34 and XBQ5), were all characterized as Bradyrhizobium species. Strains XBD2 and XS34 had a 100\% nucleotide similarities with Bradyrhizobium zhangangens and $B$. centrosematis using the blastn comparisons of both the $\mathrm{NCBI}$ and EzBiocloud servers; whereas the other cowpea miscellany strain XBQ5 was similar to $B$. elkani with $97.1 \%$ nucleotide similarity (Table 4). Based on the number and quality of nodules (pink nodules that indicate the potential for active nitrogen fixation) formed per plant, Bradyrizobium zhangangens strain XBD2 and Bradyrhozobium cenrosematis strain XS34 are the most compatible rhizobia with specific landraces of bambara groundnut in this study. The next most compatible rhizobium interaction made with the bambara groundnut landraces in terms of nodulation was by Bradyrhizobium elkani strain XBQ5.

All the three Bradyrhizobium species that formed pink nodules in their compatible bambara groundnut landraces after inoculation have very distinct phylogenetic placements on the Maximum Likelihood tree. This is an indication that bambara groundnut can form effective symbiotic interaction with phylogenetically diverse group of rhizobia, and hence shows less preference to a specific rhizobia unlike several strain specific legumes. Other studies also indicated, despite the fact that the bambara groundnut shows increased symbiotic efficiency and yield with Bradyrhizobium species, it is non-selective in its 
rhizobium requirements (Dakora and Muofhe 1995; Benson et al. 2015). It has also been demonstrated that this legume showed the ability to grow in contrasting soil conditions of different agro ecological zones and nodulated with a wide range of bacteria (Mohale et al. 2013; Benson et al. 2015). These workers also reported that, in addition to Bradyrhizobium species, nodulation of bambara groundnut also occurs by other members of the a-and $\beta$-Proteobacteria such as Rhizobium, Azorhizobium, Ensifer, Mesorhizobium and Burkholderia species. In the current study, strain UD 5 characterized as Rhizobium tropici (98\%) was the least compatible rhizobium with bambara groundnut. This is interesting since, according to the cross inoculation group concept, Rhizobia spp. that normally form nodules and fix atmospheric nitrogen in common beans and soybeans do not nodulate other legume species (Grönmeyer et al. 2014). As the rhizobium strain UD5 was originally isolated from active nodules of Phaseolus sp. (beans), it belongs to the bean inoculation group and failed to nodulate effectively with bambara groundnut ( $V$. subteranea (L.) Verdc), which is grouped under the cowpea miscellany cross inoculation group together with cowpea, peanut, groundnut, and several others. Likewise, strain WB1 which was identified as Bradyrhizobium elkani and was originally isolated from soybean failed to nodulate with bambara groundnut, signifying that rhizobia strains from the soybean inoculation group have less interaction with bambara groundnut roots and will not nodulate effectively.

Results from a wide range of investigations conducted on the symbiotic properties of legume and their microsymbionts demonstrate a strong positive correlation between nodulation and plant biomass. There is, however, very little correlation between the number of nodules per plant and plant fresh and dry weight observed in this study. This could probably be explained by the fact that, despite inducing nodulation, there was very little nitrogen fixation by the nodulating strains of Rhizobia spp. used in this study. The large percentage observed in the coefficient of variation (CV\%) among the treatments for nodule formation might be due to the wide genetic variation among the land races, the bacterial strains and their interactions, in which in some cases there was not even a single nodule formed. Despite the lack of the Ncontent and the measurements of the N2-fixation by the symbiotic interactions between the rhizobia strains and the bambara groundnut landraces, this study provides useful information on the nodulation compatibility of bambara groundnut by several members within the Bradyrhizobium spp. The study therefore warrants further field nodulation compatibility assays by testing more group of rhizobia from both the cowpea miscellanea (cross inoculation) group and other Rhizobia spp. with additional evaluation parameters such as the rate of symbiotic nitrogen fixation (SNF). This will enable the identification of bambara groundnut genotypes and their compatible rhizobia for the successful nodulation, nitrogen fixation and yield improvement of this underutilized legume.

\section{Declarations}

Acknowledgements The authors would like to acknowledge the ARC-Plant Health and Protection (ARCPHP) and the ARC-Vegetables Industrial and Medicinal Plants (ARC-VIMP), South Africa for the valuable financial, material and moral support rendered to execute this research. 
Author contributions Al, AvV and ASG conceived and designed the experiments. Al, FLB, AvV and ASG performed the glasshouse experiments. Al performed the molecular characterization of the bacterial strains and analyzed the data. Al wrote the first draft of the paper and all authors contributed in the preparation of the final manuscript draft.

Funding This research received financial support from the Agricultural Research Council Rhizobium Culture Collection project, with project number P06000137-03.

Availability of data The rhizobium $16 \mathrm{~S}$ ribosomal RNA sequence data is deposited at the National Center for Biotechnology Information (NCBI) data base library, which can be accessed at https://www.ncbi.nlm.nih.gov/genbank/.

Conflict of interest The authors declare that there is no conflict of interest of any kind.

\section{References}

1. Addinsoft (2016) Data Analysis and Statistical Solution for Microsoft Excel. Paris, Pentreath

2. Bennett AE, Daniell TJ, White PJ (2013) Benefits of breeding crops for yield response to soil organisms. In de Bruijn FJ (ed) Mol Microb Ecol of the Rhizosphere, 1st edn.John Wiley and Sons Inc, pp.17-27

3. Benson O, Beatrice A, Regina N, Koech PK, Skilton RA, Franceska S (2015) Morphological, genetic and symbiotic characterization of root nodule bacterial isolated from bambara groundnut (Vigna subterranea L. Verdc.) from soils of Lake Victoria basin, Western Kenya.J Appl Biol Biochem3:1-10

4. Collison ST, Clawson EJ, Azam-Ali SN, Black CR (1997)Effects of soil moisture deficits on the water relations of bambara groundnut (Vigna subterranea L. Verdc.).J Exp Bot48:877-884

5. Dakora FD, Muofhe LM (1995) Nitrogen fixation and nitrogen nutrition in symbiotic bambara groundnut (Vigna subterranea L. Verdc.) and Kersting's bean (Macrotyloma geocarpum (Harms) Maréch.et Baud.). In: Heller JFB and Mushonga J(eds.) Proceedings of the workshop on conservation and improvement of bambara groundnut (Vigna subterranea L. Verdc.),1416November, Harare Zimbbabwe

6. Doku EV (1969) Host specificity among five species in the cowpea cross inoculation group.Plant Soil30 -128

7. Elliott GN, Chou J-H, Chen W-M, Bloemberg GV, Bontemps C, Martinez-Romero E, Velazquez E Young Sprent JPW, James JI EK (2009) Burkholderia spp. are the most competitive symptoms in Mimosa particularly under N-limited conditions.Environ Microbiol11:762-778

8. Gnangui SLE, Kouadjo CGZ, Zeze A (2019) First report of Rhizobium pusense within Voandzou (Vigna subterranea (L.) Verdc.) rhizosphere in Cöte d'Ivoire. Microbiol Nature 1: 55-65

9. Graham PH, Hungria M, Tlusty B (2004) Breeding for better nitrogen fixation in grain legumes. Where do the rhizobia fit? Crop Management. doi:10.1094/CM-2004-0301-02-RV 
10. Grönemeyer JL, Kulkarni L, Berkelmann D, Hurek T, Reinhold-Hurek B (2014) Rhizobia indegenous to the Okavango region in Sub-Saharan Africa: Diversity, adaptation and host specificity.Appl Env Microbiol 80.: $7244-7256$

11. Guar YD, Sen AN (1979) Cross inoculation group specificity in Cicer rhizobium symbiosis New Phytol 83:745-754

12. Howieson JG, Dilworth MJ (eds) Working with rhizobia.Australian Center for International Agricultural Research (2016) pp.90, Canbera

13. Johnson DT (1968) The bambara groundnut: a review. Rhodesia Agric J 65:1-4

14. Katoh K, Kazuharu MK, Kuma K-I, Miyata T (2022) MAFFT:a novel method for rapid multiple sequence alignment based on fast Fourier transform.Nucleic Acids Res30:3059-3066

15. Kumar S, Stecher G, Li M, Knyaz C, Tamura K (2018) MEGA X:Molecular Evolutionary Genetics Analysis across Computing Platforms.Mol Biol Evol35:1547-1549

16. Lindstroom K, Mousavi SA (2020) Effectiveness of nitrogen fixation in rhizobia. Microb Biotech (5): 1314- 1335

17. Masindeni DR (2006) Evaluation of Bambara groundnut (Vigna subterranea). for stability and related yield characteristics. MSc Thesis, University of Free State

18. Masson-Biovin C, Sachs JL (2018) Symbiotic nitrogen fixation by rhizobia- The roots of a success story CurrOpin Plant Biol44:7-15

19. Mkandawire $\mathrm{CH}$ (2007) Review of bambara groundnut (Vigna subterranea L. Verdc) production in Sub-Saharan Africa.Agric. Journal2(4):464-470

20. Mohale CK, Belane AK, Dakora FD (2013) Why is bambara groundnut able to grow and fix N2 under contrasting soil conditions in different agroecologies. Proceeding of the 3rd International Scientific Conference on neglected and underutilized species, Accra, Ghana, 25-27 September, pp 11

21. Mubaiwa J, Fogliano B, Chidewe C, Bakker EJ, Linneman AR (2018) Utilization of bambara groundnut (Vigna unguiculata (L.) Verdc. for sustainable food and nutrition security in semi-arid regions of ZimbabwePLoS ONE13 (10):e0204817

22. Murevanhema YY, Jideani VA (2013) Potential of bambara groundnut (Vigna subterranea L.Verdc) milk as a probiotic beverage.Crit Rev Food Sci Nutr53:954-967

23. Puozaa DK, Jaiswal SK, Dakora FD (2017)African origins of Bradyrhizobium populations nodulating bambara groundnut (Vigna subterranea L. Verdc) in Ghanaian and South African soils.PLoS One (9): e0184943

24. Reinprecht Y, Scharm L, Marsolias F, Smith TH, Hill B, Pauls KP (2020) Effects of nitrogen application on nitrogen fixation in common bean production.Front Plant

Sci11:1172.doi:10.3389/fpls.2020.01172

25. Sarr PS, Yamakawa T, Fujimoto S, Saeki Y, Thao HTB, Myint AK (2009) Phylogenetic diversity and symbiotic effectiveness of root nodulating bacteria with cowpea in the South West area of Japan MicrobesEnviron24:105-112 
26. SAS Institute Inc (2016) SAS ${ }^{9} 9.4$ Language Reference: Concepts, Sixth Edition. SAS Institue Inc, Cary, NC

27. Somasegaran P, Abaidoo RC, Kumaga F (1990)Host Bradyrhizobium relationships and nitrogen fixation in the Bambara groundnut (Voandzeia subterranea (L.) Thouars nom. Cons.).Trop Agri67:16

28. Somasegaran P, Hoben HJ (1994) Hand book for rhizobia: Methods in Legume-Rhizobium Technology Springer-Verlag New York

29. Sprent JI, Odee DW, Dakora FD (2010) African legumes: A vital but underutilized resources.J Exp Bot61 -1265

30. Swanevelder JC (1998) Bambara food for Africa. (Vigna subterranea- bambara groundnut) National department of Agriculture. ARC-Grain Crops Institure, South Africa

31. Weisburg WG, Barns SM, Pelletier DA, Lane DJ (1991) 16S ribosomal DNA amplification for phylogenetic studyJ Bacteriol173:697-703

32. Yoon SH, Ha SM, Kwon S, Lim J, Kim Y, Seo H, Chun J (2017) Introducing EzBioCloud. A taxonomically united database of $16 \mathrm{~S}$ rRNA and whole genome assemblies. Int J Syst Evol Microbiol 67.:1613-161

\section{Figures}



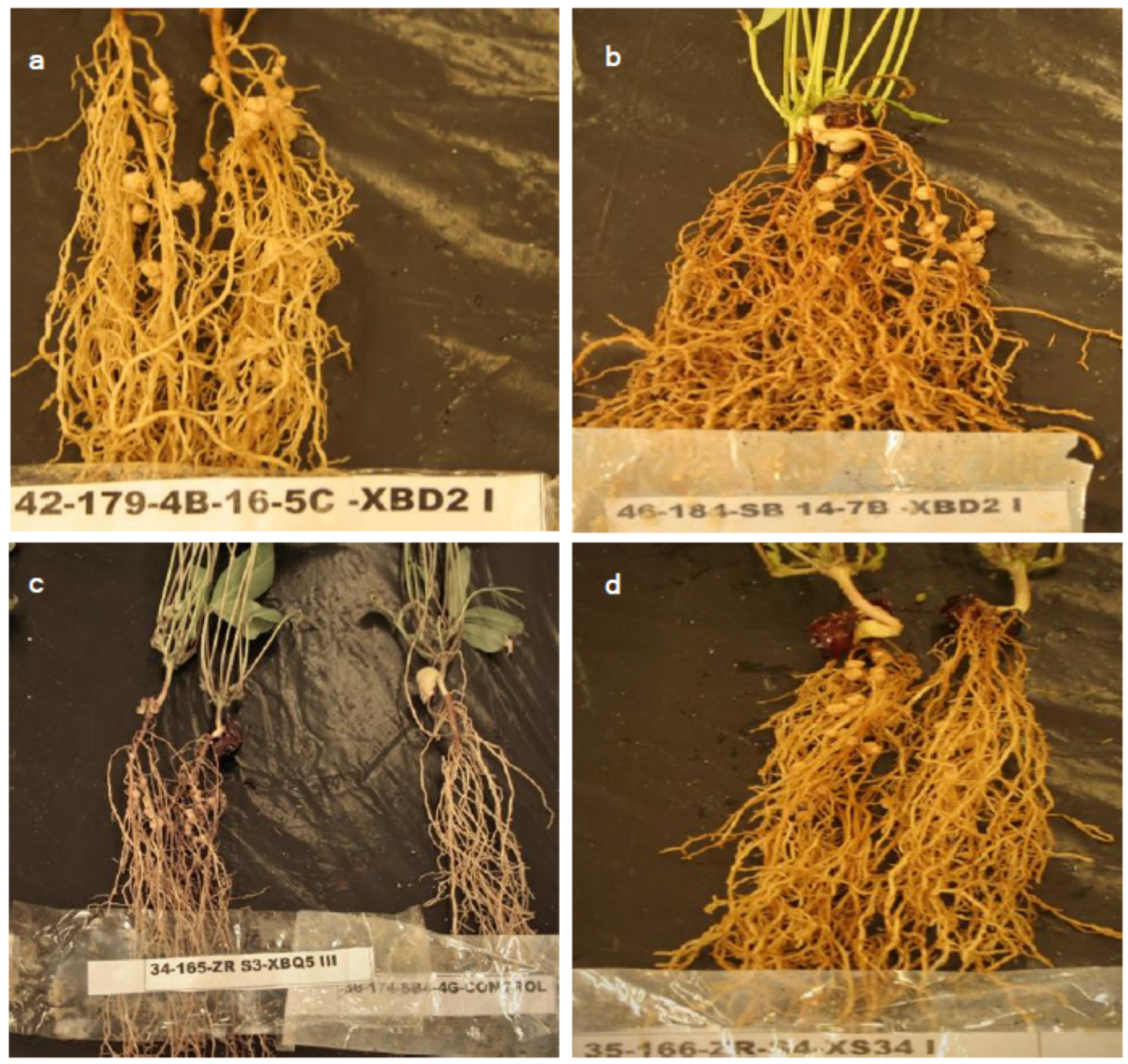

\section{Figure 1}

Nodulation of representative landraces of Vigna subterranea L. Verdc. by Bradyrhizobium zhangangense strain XBD2 (a \&b), B. elkani strain XBQ5 (c) and B. centrosematis strain XS34 (d). Non-inoculated plants in $\mathrm{c} \& \mathrm{~d}$ (right) did not form any nodules. 

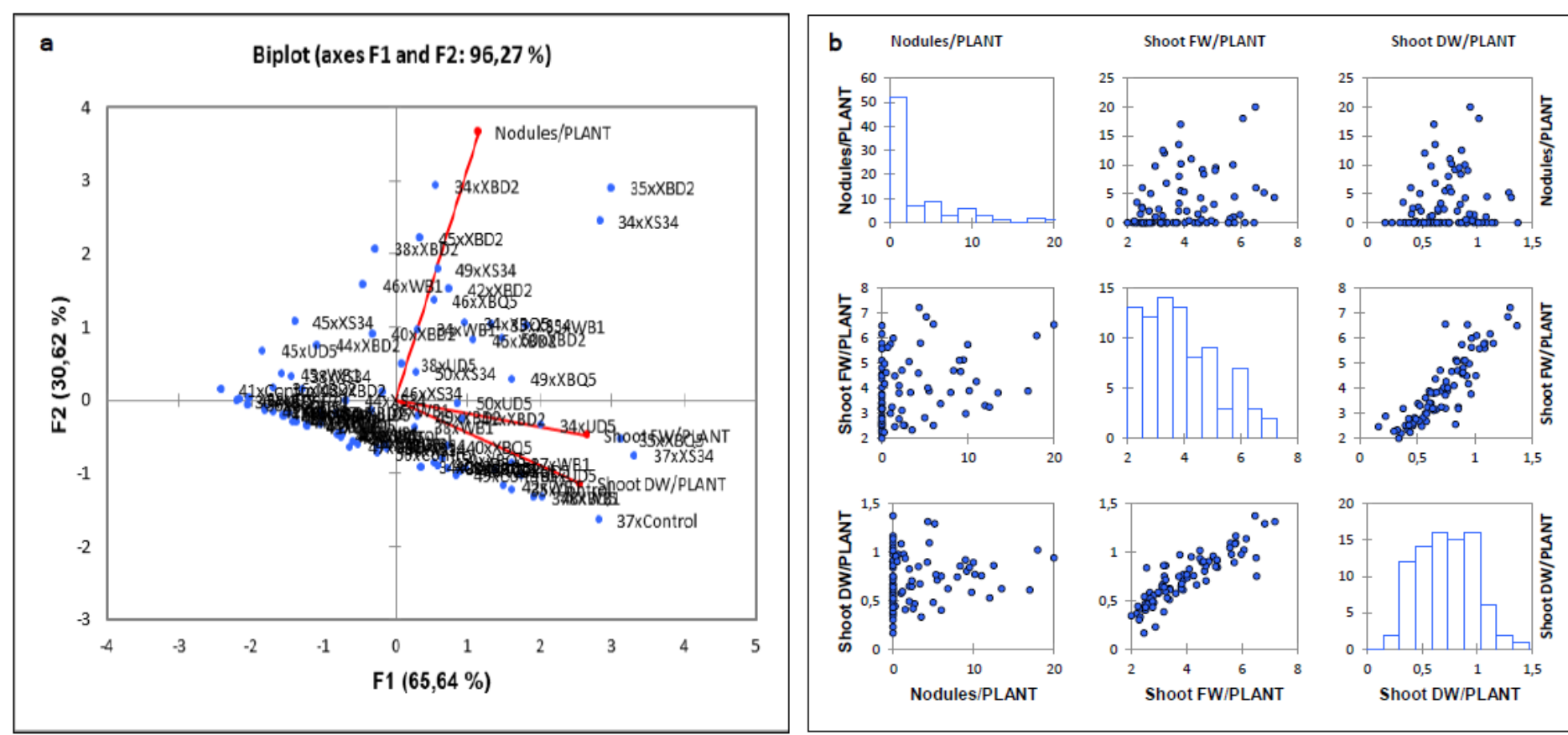

\section{Figure 2}

Principal component analysis (PCA) biplot (axes F1 and F2: $95.26 \%$ ) of mean nodule number, fresh weight and dry weight. Note that nodule number per plant has higher values on both principal coordinates (F1 \& F2). Whereas fresh weight and dry weight are represented by positive scores only on the first coordinate (F1) and negative or close to zero scores on the second coordinate (F2). The highest compatibility in terms of nodule formation is shown for rhizobia strain XBD2 vs genotype \#35 and rhizobia strain XS34 vs genotype \#34 (a). Scatter plot showing the correlational relationship between nodule number and plant biomass. A clear positive correlation exists between shoot fresh and dry weights, which was also evident from the biplot graph indicated above (b) 


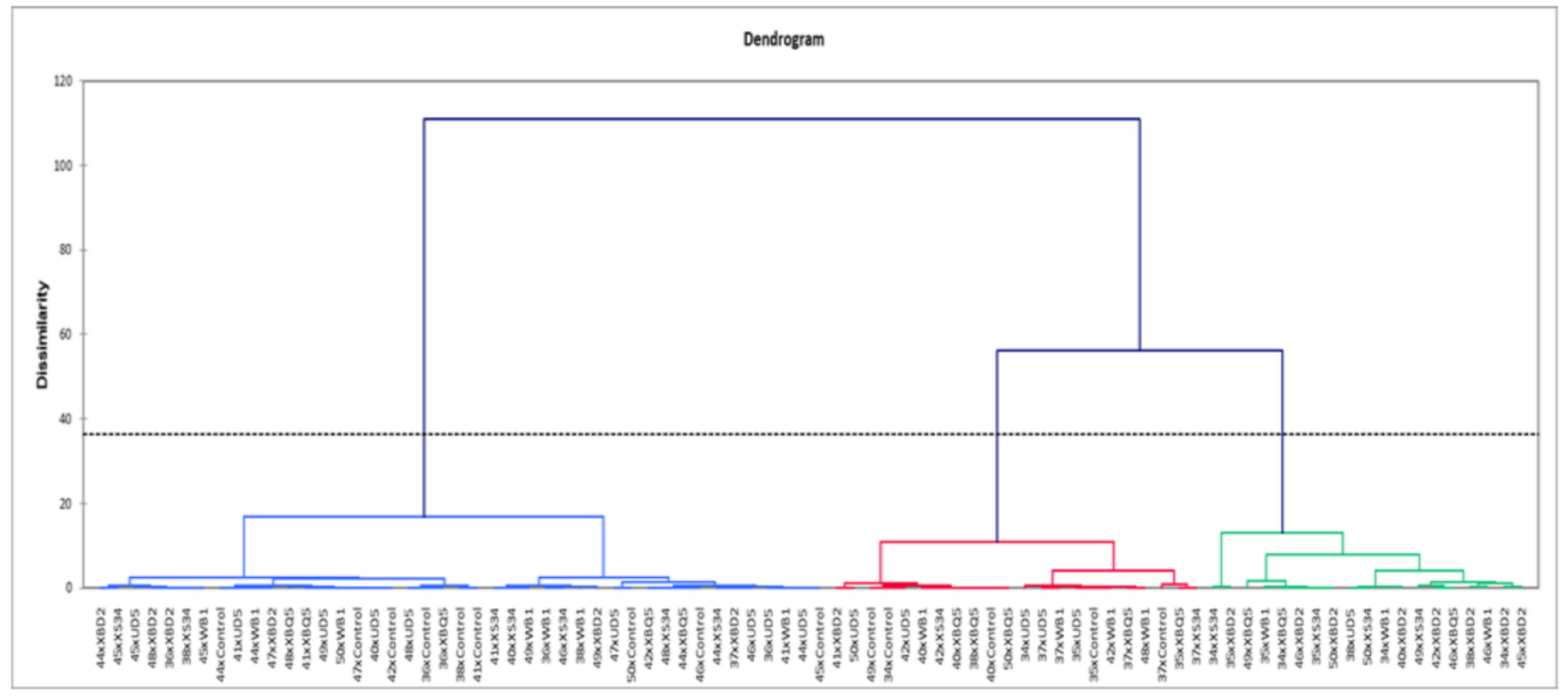

\section{Figure 3}

Hierarchical clustering of the interaction (genotype $\mathrm{x}$ rhizobia strain) that formed three major clusters. Note that based on their nodulation compatibility and symbiotic interactions, three major clusters containing six sub- clusters were formed. The clusters with the most compatible rhizobium strains and bambara seed landraces are colored in green where the Bradyrhizobium strain XBD2 showed significant symbiotic properties with landraces $34,35,38,40,42,45,46,49$, and 50 


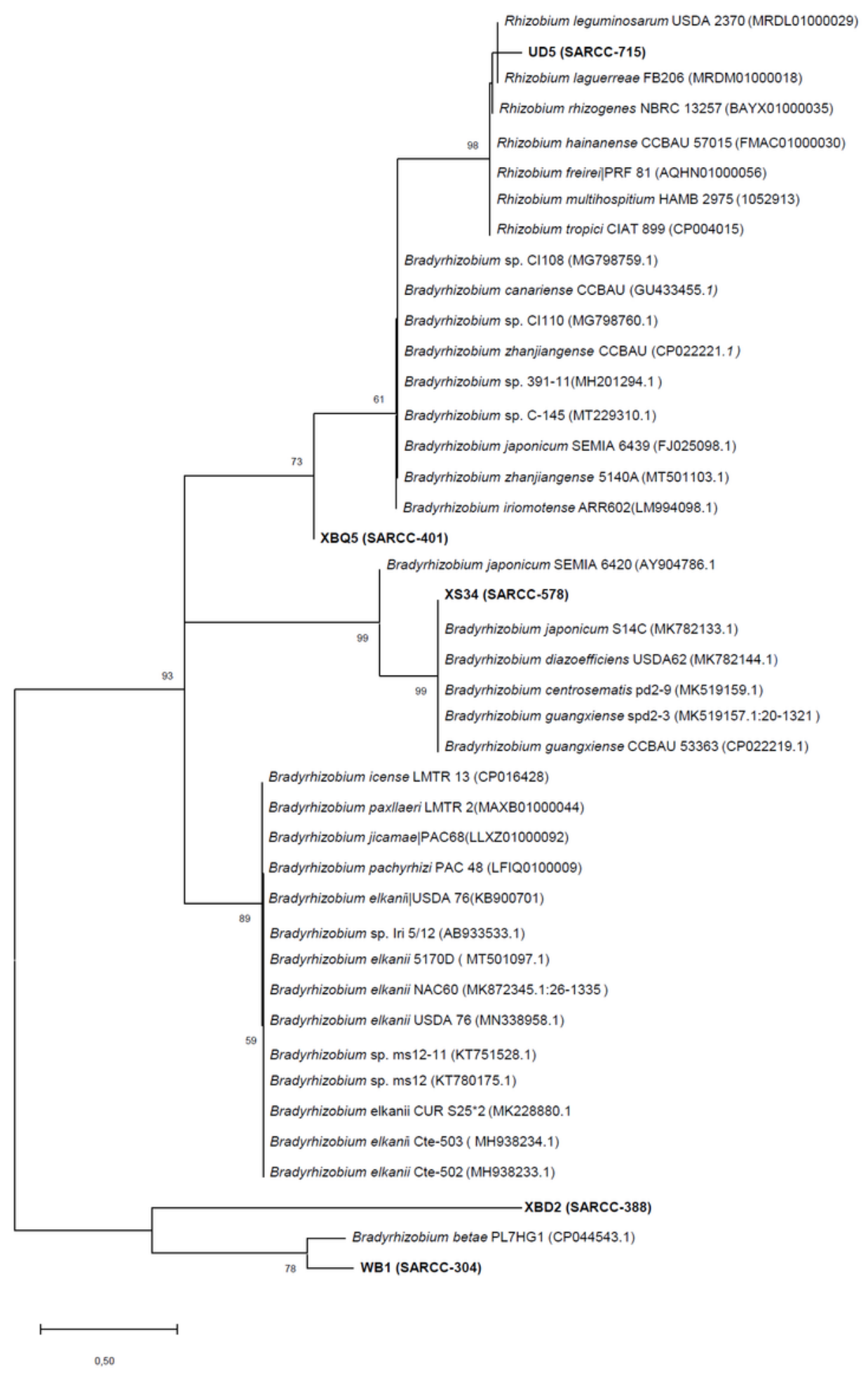

\section{Figure 4}

Maximum Likelihood (ML) tree elucidating the phylogenetic positions and evolutionary relationship of the five rhizobia strains in this study (in bold) with 37 rhizobia strains retrieved from the NCBI database. Numbers in the parenthesis represent the NCBI accession numbers. The tree is drawn to scale with branch lengths indicating the number of nucleotide substitution per site 
Page 24/24 